\title{
Factors Affecting Biodegradation of the Organophosphorus Insecticide Diazinon by Bacterial Mono-Culture of Bacillus Sefensis 7, Isolated From the Rhizosphere of Date Palm Tree
}

\author{
Magda M. Aly ${ }^{1.2 *}$, Buthinah A. Al-aidaroos ${ }^{1}$ and Fahad A. Alfassi ${ }^{1}$ \\ ${ }^{1}$ Biology Department, Faculty of Science, King Abdulaziz University, Saudi Arabia \\ ${ }^{2}$ Botany Department, Faculty of Science, Kafr el-Sheikh University, Egypt
}

\begin{abstract}
Due to widespread use pesticides for crop protection, they are considered as contaminants in the, environmental matrices such soil which are exposed to large quantities. Three isolates from soil samples using enrichment culture technique have been isolated and grown in the minimal growth medium where Diazinon served as a sole carbon source $(60 \mathrm{mg} / \mathrm{l})$. Total three bacterial strains were screened for Diazinon degradation. The most active one was isolate BMNF7 (33\% degradation. Lower degradation percentages were recorded for the two other isolates, BMRF3 and BMTF 8 (21-30\%). The isolate BMNF7 was identified by morphological and biochemical studies as Bacillus sp. and identification was confirmed using 16srRNA. It was identified as Bacillus sefensis 7 and this isolate was able to degrade up to $63 \%$ of Diazinon $(60 \mathrm{mg} / \mathrm{l})$ in mineral salt medium $(M S M)$ as a sole carbon source within 10 days of incubation. The bacterial growth and Diazinon degradation were accelerated when MSM supplemented with $0.75(\mathrm{~g} / \mathrm{l})$ yeast extract and $0.5 \mathrm{~g} / \mathrm{l}$ glucose as an additional carbon and nitrogen sources. The maximum degradation was obtained at $\mathrm{pH} 7$ and $45^{\circ} \mathrm{C}$ after 10 days of incubation and using $4 \times 10^{6} \mathrm{CFU} / \mathrm{ml}$ as inoculum size. It was noticed that the best growth temperature was $37^{\circ} \mathrm{C}$ while the maximum degradation was at $45^{\circ} \mathrm{C}$, meaning that high temperature increased degradation process. In conclusion the bacterial strains isolated from the agricultural soil, especially Bacillus species showed the ability to degrade Diazinon insecticide and optimization of growth conditions enhanced the percentage of degradation.
\end{abstract}

Keywords: Bacillus, Diazinon, Insecticide, Degradation, 16srRNA.

\section{Introduction}

Although, Phoenix dactylifera L., Date palm, is one of the oldest trees in the world, the effective insect weevil or Oliver (Rhynchophorus ferrugineus) destroys the tissues of the trunk, leading to the falling of the tree (Kamil and Naji, 2012). Organophosphate (OP) pesticides specially Diazinon is used worldwide to control this insect through the inhibition of acetyl cholin esterase (Theriot and Grunden, 2011, Singh and Walker, 2006). Diazinon which is widely employed in agriculture (Khani and kafilzadeh, 2014) is highly toxic to man and animals and the residues found in the environment has many health hazards (Chapalamadugu and Chaudhry, 1992), thus its biodegradation by bacteria is very necessary (Ghosh et al., 2010). The non-systemic insecticide Diazinonis is synthetic, colorless to dark brown liquid with average half life of 30 days when applied to soil and with chemical structure of $\mathrm{O}$, O- diethyl 0- 2- isopropyl- 4-methyl -6- pyrimidyl phosphorothioate (Mallick et al., 1999, Khani and kafilzadeh, 2014). Diazinon is an organophosphorous compound very effective for the control of ecto-parasites. Biodegradation of insecticides in soil differed with their chemical properties, type of soil and microorganism activities (Kennenth, 1990). Application of pesticides to soil cause changes in the soil microflora, decreased soil fertility, crop production, $\mathrm{N}_{2}$ fixition by soil microorganisms, symbioses in plants, nodulation in legumes and growth of cellulolytic, phosphate solubilizing and nitrifying bacteria (Jarallah et al., 2016). Complete degradation of a parent compound by specific enzymes provides both carbon and energy for the growth and reproduction of microbes (Singh, 2008).

The diversity of bacterial communities associated with the date palm root system was investigated through the analysis of the diversity of the 16S rRNA gene in the rhizosphere and root surrounding soil fractions. It was found that the south region (closest to desert) presents harsher conditions that select a more restricted type of bacteria (Ferjani et al., 2015). These ecological islands represent specific cluster of biological diversity that may contribute to the overall regional bacterial community functionality and furthermore increase the level of resilience to environmental change of the entire system (Anderson et al., 2008). Therefore, the aim of this study was isolation and characterization of indigenous bacteria capable of metabolizing Diazinon as a sole energy and carbon sources and to fulfill this aim, a soil samples were collected from Diazinon contaminated soil of the rhizosphere of date palm root system. Factors affecting degradation were also studied. 
Collection of soil sample

\section{Material and methods}

Contaminated soil samples were collected from different date palm farms in western region, Saudi Arabia, in sterilized screw-capped test tubes for bacterial isolation. The samples were transferred to the laboratory and $1.0 \mathrm{~g}$ of each soil sample was suspended in a $250 \mathrm{ml}$ conical flask containing $50 \mathrm{ml}$ mineral salts (MS) medium enriched with Diazinon $(0.1 \% \mathrm{v} / \mathrm{v})$ as a sole carbon source. The composition mineral salts medium was (g/l): $1 \mathrm{~g}\left(\mathrm{NH}_{4}\right)_{2} \mathrm{SO}_{4}, 0.8 \mathrm{~g} \mathrm{~K}_{2} \mathrm{HPO}_{4}, 0.2 \mathrm{~g} \mathrm{KH}_{2} \mathrm{PO}_{4}, 0.2 \mathrm{~g} \mathrm{MgSO}_{4} \cdot 7 \mathrm{H}_{2} \mathrm{O}, 0.1 \mathrm{~g} \mathrm{CaCl} \cdot 2 \mathrm{H}_{2} \mathrm{O}$, and 5 $\mathrm{mg} \mathrm{FeSO} 4 \cdot 7 \mathrm{H}_{2} \mathrm{O}$. The medium $\mathrm{pH}$ was adjusted to $\mathrm{pH} 7$ (Wu et al., 2013). Flasks were placed in a shakingincubator at 100rpm for 10 days. To ensure the ability of Diazinon degradation by bacteria, subsequent transfer of inoculum (3\%) into a fresh MS medium containing increasing concentration of Diazinon was carried out. The used concentration of Diazinon was 0.1-6.0 \% where very small colonies were obtained.

\section{Isolation, purification and preservation of the strain}

Aliquots $(100 \mu \mathrm{l})$ from the Diazinon-enriched medium were streaked on both MS agar containing the tested concentration of Diazinon and Nutrient agar plates. All plates were incubated at $45^{\circ} \mathrm{C}$ for 7 days. Single colonies were picked up and subcultured into fresh MS agar amended with Diazinon until pure colonies were obtained. All pure colonies were preserved on Nutrient agar slants at $4^{\circ} \mathrm{C}$ or in $10 \%$ sterile glycerol at $70^{\circ} \mathrm{C}$.

\section{Measuring Diazinon degradation on solid medium}

Each selected bacterial culture was inoculated in the central of agar plat congaing MS agar medium with $5 \% \mathrm{v} / \mathrm{v}$ Diazinon which equal to $50 \mathrm{mg} / \mathrm{l}$. All plates were incubated at $45^{\circ} \mathrm{C}$ for 10 days. All plates were examined and clear zone diameter $(\mathrm{cm})$ was measured three times following by mean value calculation.

\section{Morphology of colony and cells}

The morphological characteristics of the colony; pigmentation, diameter, elevation and transparency was determined visually of $24 \mathrm{hrs}$ old colony growing on Nutrient agar medium and incubated at $45^{\circ} \mathrm{C}$.Cell shape, arrangement and reaction to the gram staining were assessed.

\section{Biochemical characterization using the API50Ch strip kit}

In order to investigate the biochemical characteristics of the strain API50Ch strip kit (Biomerieux, France) was used following the guidelines of the manufacturer. Results were recorded after 48hrs of incubation of API50Ch.

\section{Identification of the strain using Vitek compact II}

The bacterial strain DDK6 was identified using the automated system for identification of bacterial strains, Vitek compact II. Gram-Positive Card was used and the data analysis was carried out using the Software version: 05.02 (Biomerieux, Mary L'Etoile, France).

\section{Identification of the isolates using $16 \mathrm{~S}$ rRNA gene sequencing}

$16 \mathrm{~S}$ rRNA gene was amplified using the universal primers 27F 5'-AGAGTTTGATCMTGGCTCAG-3' and 5'TACGGYTACCTTGTTACGACTT-3' (Weisburg et al., 1991), in $20 \mu$ total PCR reaction. Genomic DNA was extracted from the strain using the InstaGene Matrix (Bio-Rad, USA) following the instructions of the manufacturer. PCR conditions were adjusted as previously described (Khalifa et al., 2015).For sequencing of the 16S rRNA gene, the Big Dye terminator cycle sequencing kit (Applied BioSystems, USA) was used. Sequencing products were resolved on an Applied Biosystems model 3730XL automated DNA sequencing system (Applied BioSystems, USA) as described in Chun et al., 2007, Tamura and Nei, 1993,Tamura et al., 2011).

\section{Measuring bacterial growth}

Bacterial growth in MS broth medium was determined by measuring the Absorbance at $550 \mathrm{~nm}$. Moreover, after collecting the bacterial growth and centrifugation at 10,000 rpm, cell packed volume (CPV)/l were determined (George, 1990, Agwa et al., 2000)

\section{Sample preparation and Diazinon detection using HPLC}

The liquid chromatographic system (Waters 2690 separation module) with a column $(2 \mathrm{~cm} \times 4.0 \mathrm{~mm}, 5$ $\mu \mathrm{m})$ and a reversed-phase $\mu$ Bondapak 125A C18 column $(10 \mu \mathrm{m}, 3.9 \times 300 \mathrm{~mm})$ were used (Product Number: WAT027324). $\mu$ Bondapak C18 columns are general purpose, silica-based, reversed-phase $\mathrm{C} 18$ columns that are based on $10 \mu \mathrm{m}$ particle technology. Samples were acidified with 1M acetic acid (pH 5.0). Disposable C18 SepPak cartridges were conditioned with $3 \mathrm{ml}$ of acetonitrile then equilibrated using $3 \mathrm{ml}$ of water prior to use. After vortex for $30 \mathrm{sec}$, the sample was centrifuged for $5 \mathrm{~min}$ at $1000 \mathrm{rpm}$ and the supernatant was loaded into the disposable cartridges for elimination of waste, then washed with $2 \mathrm{ml}$ of water, eluted twice by $2 \mathrm{ml}$ of methanol in a marked small test tube, and reduced to $500 \mu \mathrm{l}$ using a gentle stream of nitrogen prior to analysis by HPLC. The chromatographic conditions applied were as the following: A 10- $\mu 1$ solution was injected into 
the HPLC and the mobile phase was a water-acetonitrile gradient at a flow rate of 1 to $1.5 \mathrm{ml} / \mathrm{min}$. The water was adjusted to $\mathrm{pH} 3.0$ using $1 \mathrm{M}$ acetic acid. The gradient started at $1 \%$ acetonitrile, increased to $55 \%$ acetonitrile at the 6-min mark, and then increased to $80 \%$ acetonitrile at $11 \mathrm{~min}$. The system then returned to $1 \%$ acetonitrile at $13 \mathrm{~min}$ and was kept under this condition for $3 \mathrm{~min}$ in order to re-equilibrate. The eluents were monitored by the UV detection of the wavelengths $254 \mathrm{~nm}$. The chromatographic analysis was performed at ambient temperature. Calibration procedures of a Diazinon were prepared in acetonitrile. Their concentrations ranged from 200 to $2000 \mathrm{ng} / \mathrm{ml}$. Linear calibration curve was obtained by plotting the peak areas of the individual compounds as a function of the concentration. The standard curves were used to determine Diazinon, limits of detection (LODs) and limits of quantization were determined at the lowest concentration to be detected and quantified of Diazinon, taking into consideration a 1:3 and 1:10 ratio of the baseline noise and calibration point, respectively. The results were repeated five times for confirmation.

\section{Results}

The collected soil samples were from 8 date farms, located in western region, Saudi Arabia. About 1.0 $\mathrm{g}$ of each soil was used to isolate bacteria in minimal salt broth medium containing Diazinon $0.1 \% \mathrm{v} / \mathrm{v} \quad(1.0 \mathrm{ml} / \mathrm{l}$ of standard solution). After growth for 10 days, the cells were transferred to new medium containing increasing concentration of Diazinon. After each transfer bacterial growth was checked on NA medium. After increasing concentration of Diazinon, number of bacterial isolates was decreased up to 3 isolates at $50 \mathrm{ml} / \mathrm{l}$ equal to 50 $\mathrm{mg} / \mathrm{l}$ Diazinon. Finally by visual observation, among the well and faster growing bacterial isolates three were selected and designated as (BMR3), (BMN7) and (BMT8). These isolates were picked at $45^{\circ} \mathrm{C}$ and $50 \mathrm{ml} / 1$ Diazinon. These isolates were preserved on agar slants at $4^{\circ} \mathrm{C}$ or in $10 \%$ sterile glycerol until used for further details studies.

All bacterial isolates were sub-cultured on both Diazinon mineral salt agar and broth media containing the same concentration of Diazinon and all plate and inoculated flasks were incubated $45^{\circ} \mathrm{C}$ and the growth, clearance zones of Diazinon degradation and \% of degradation were measured for each isolate. The diameter of clear zones were ranged from 4.1-7.0 cm and maximum diameter was for the isolate BMNF7 (Table 1). The \% of degradation was ranged from 21-33\%. BMNF7 was selected for detail studies and its cultural characteristics were determined. It formed a yellowish white, convex colony, with a diameter of 2 to $3 \mathrm{~mm}$, and entire margin. Cells were rod shape with a terminal endospores and exhibited positive reaction to the Gram staining (Fig. 1). These features were typical to the type strains of the genus Bacillus. For confirming the identity biochemical characterization using API50Ch strip kit containing 50 biochemical tests designated to estimate the carbohydrate metabolism ability of a microorganism was carried out. The system is exploited in the current study as a fast, effective a reliable tool to study the metabolic versatility of the strain BMNF7 towards different sources of carbohydrate. It exhibited the ability to utilize a wide range of different carbon including monosaccharides (e.g., D-galactose and L-arabinose) disaccharides (e.g., D-maltose and D-lactose), polysaccharides (e.g., Starch and Glycogen) and sugar alcohols (e.g., D-galactose, D-mannitol). Out of 49 used sugars, it utilizes $35(\sim 75 \%)$ different carbon source while about $25 \%$ of the carbon compounds were not utilized. The biochemical profile of the BMNF7 using API 50CH kit strip is typical to that of the genus Bacillus. Vitek II is a powerful and accurate automated platform with an expanded identification database for rapid microbial identification, and antibiotic susceptibility testing based on biochemical analysis using colorimetric method. The bacterial BMNF7 was identified as Bacillus by the Vitek compact II. This indicated that this tool is efficient for bacterial identification at the genus and specific levels. The 16S rRNA gene sequencing is a well-established technique for a robust and accurate bacterial identification and for inferring phylogenetic relationships among species. Comparative analyses of the $16 \mathrm{~S}$ rRNA gene sequencing revealed that the strain BMNF7 was related to the genus Bacillus. Sequence analysis showed that BMNF7 was most closely related to Bacillus pumilus (95\% identity), at similarity levels of gene sequences. As can be seen in Fig. 2, the neighbour-joining phylogenetic tree clearly highlighted that the strain BMNF7 grouped with the Bacillus safenis. This isolate was able to degrade $60 \%$ Diazinon in mineral salt medium (MSM) as a sole carbon source within 10 days of incubation. The bacterial growth and Diazinon degradation were accelerated when MSM supplemented with 0.75 (g/l) of yeast extract (Fig. 3) and 0.5 g/l glucose (Fig. 4) as an additional carbon and nitrogen sources. The maximum

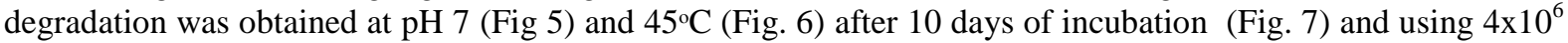
$\mathrm{CFU} / \mathrm{ml}$ as inoculum size (Fig. 8). In conclusion the bacterial strains isolated from the agricultural soil, especially Bacillus species showed the ability to degrade Diazinon insecticide and optimization of growth conditions enhanced the percentage of degradation. 


\section{Discussion}

The soil with previously used pesticide contained different microbes that can use these materials and this may due to outcompeting, biotic and/or abiotic interacting factors. Therefore, isolation of new bacterial strains adapted to the local conditions of a particular area is crucial for the efficiency of pesticide removal in this area (Wu et al. 2013). Many microorganisms can survive in pollutant environment due to the potential to degrade substance that harmful to our environment like chemical fertilizers and pesticides (Mahiudddin, 2014). In this study, soil samples had been taken from date farms in Saudi Arabia and isolation of the microorganisms from soil with a history in using of pesticide was carried out using enrichment culture technique. Many microorganisms were isolated from soil sample using enrichment culture technique and they have been grown in the minimal salt growth medium where Diazinon served as a sole carbon source. The most active isolate was identified according to biochemical characters, API50 CH strip kit. Vitek compact II as a species of the genus Bacillus. Three bacterial strains Pseudomonas peli, Burkholderia caryophylli and Brevundimonas diminuta were isolated and screened on medium containing Diazinon as carbon source (Mahiudddin, 2014).

Bala et al., (2012) providing another evidence to the reliable identification using biochemical characterization by applying API50 CH strip kit. Vitek compact II is efficient tool for bacterial identification at the genus and species levels. The efficiency of this system to correctly identify Staphylococcus spp. and other bacterial genera has been proven previously (Chatzigeorgiou et al., 2011; Paim et al., 2014). Nonetheless, discordance between Vitek II and 16S rRNA gene sequencing for bacterial identification has been reported. For example, Vitek II identified a bacterial strain from human blood as K. kristinae (score of 98\%) whereas 16s rRNA sequencing identified it as Rothiaamarae (Abouseadaet al., 2016). Many results have been obtained by Hassan et al. (2016) which showed that both Vitek2 and 16S rRNA gene sequencing correctly identified certain bacteria (Hassan et al., 2016). Mahiudddin, (2014) used morphological and biochemical studies and 16S rRNA gene sequencing for identification of the Diazinon degrading bacteria obtained from soil. Bacterial isolates, able to grow in medium containing the individual pesticide as the carbon source, were characterized by $16 \mathrm{~S}$ rRNA gene sequencing and biochemical tests (Naphade, 2012).

In this study, Bacillus cells use Diazinon as carbon source in mineral salt medium. Similarly, the bacterial isolates Pseudomonas peli, Burkholderia caryophylli and Brevundimonas diminuta were able to completely degrade $20 \mathrm{mg} / \mathrm{l}$ Diazinon in mineral salt medium (MSM) as a sole carbon source within 12 days of incubation (Mahiudddin, 2014).more degradation was obtained by the selected Bacillus isolate $60 \%$ of $50 \mathrm{mg} / \mathrm{l}$. Optimization of growth conditions enhanced growth and Diazinon degradation by Bacillus. Growth was determined using both absorbance at $550 \mathrm{~nm}$ and CPV/l. Cell packed volume is ideal for the monitoring of the growth and cell mass (George 1990, Agwa et al., 2000). Addition of yeast extracts (0.75 g/l and glucose enhancing Diazinon degradation. Similarly, the bacterial growth and Diazinon degradation by the bacterial isolates Pseudomonas peli, Burkholderia caryophylli and Brevundimonas diminuta were accelerated and the isolates were able to completely degrade $20 \mathrm{mg} / \mathrm{l}$ Diazinon in mineral salt medium as a sole carbon source within 12 days of incubation (Mahiudddin, 2014). When MSM supplemented with $0.5 \%$ of glucose and/or yeast extract as an additional carbon and nitrogen sources, degradation rate was increased and there is a correlation among Diazinon degradation, microbial growth and $\mathrm{pH}$ of the medium (Mahiudddin, 2014).

Several bacteria have been isolated to use Diazinon compound as a source of carbon, nitrogen or phosphorus (Phugare and Swapnil Suresh, 2011, Siddavattam et al., 2003, Phugare and Swapnil Suresh, 2011). The genera Neisseria, Veillonella, Micrococcus and Staphylococcus were recorded for bioremediation technique in degrading pesticide (Adawiyah, 2008). In the presence of carbosulfan pesticide, Pseudomonas was isolated from Solanum melongena (brinjal) cultivated soil having a history of pesticide usage and this isolate was valuable for bioremediation of pesticide contaminated soils (Sharif, 2013) and there is positive correlation between pesticide degradation and tolerance to metals and antibiotics (Naphade, 2012).

Microorganisms plays a major role for saving our environments by degrading xenobiotic compounds and chemicals wastes and the rate of biodegradation by microbes depends not only on the presence of degradative enzymes, but also on a wide range of environmental parameters. Temperature, $\mathrm{pH}$, water potential, nutrients and the amount of pesticide or metabolite in soil may also act as limiting factor for pesticide degrading microorganisms (Singh, 2008). Microbial degradation of pesticide and other hydrocarbon is attributed to cytochrome $\mathrm{P} 450$, haemthiolate monooxygenases, which catalyze the oxidative addition of atomic oxygen to the C-H or C-C bond of the organic compound (Van Beilen and Funhoff, 2007). Many bacterial species possess Cytochrome P450 proteins and testing these species is crucial to confirm the ability to degrade pesticide. Other enzymes such as soluble and particulate methane monoxygenases are involved in hydrocarbon degradation (Das and Chandran, 2011).

A few consortia with the capability to metabolize Diazinon have also been reported (Singh et al., 2006, Singh et al., 2003). In general, Diazinon or Organophosphate (OP) compounds do not adversely affect bacteria, because bacteria do not possess acetylcholin esterase and some microorganisms can even use OPs as an energy source(Singh, et al., 2006) due to the presence of Phosphotriesterases. There is a correlation between treatment 
duration and \% degradation of chlorpyrifos by bacterial mono- and mixed-cultures (Kumar, 2011).A bacterial consortium of Proteus vulgaris, Vibrio sp., Serratia sp. and Acinetobacter sp. which degraded Dichlorvos was isolated from agricultural soil in medium and these isolated strains can be used for waste biodegradation or bioremediation of organophosphate pesticide- contaminated soil or water (Agarry, 2013). Pseudomonas aeruginosa and Flavimonas oryzihabitans grow on mineral medium amended with ground coffee beans and 50 $\mathrm{mg} / \mathrm{l}$ endosulfan (Barraga n-Huerta, 2007). Degradation rate was slower in lower $\mathrm{pH}$ in comparison with natural and alkaline soils and the bacterial isolates were able to rapidly degrade fenamiphos and chlorpyrifos at $15-35^{\circ} \mathrm{C}$ but their degradation ability was sharply reduced at 5 and $50^{\circ} \mathrm{C}(\mathrm{Singh}, 2006)$. In India; extensive applications of persistent organochlorine pesticides like endosulfan on cotton have led to the contamination of soil and water environments at several sites and microbial degradation using several strains of bacteria and fungi offers an effective approach to remove such toxicants from the environment (Reddya, 2012).

\section{Conclusion}

In conclusion, the bacterial strains isolated from the agricultural soil showed the ability to degrade the insecticide Diazinon and the cultural; biochemical and molecular characteristics were used for the strain BMNF7 identification which exhibited a metabolic versatility and ability to degrade pesticide, indicating ecological and environmental merits for its application in bioremediation of pesticide pollutants. Overall, this study provides the complete insight of the Diazinon degradation with the help of bacterial strains, which could be helpful to devise a proper strategy for the degradation of pesticides under field conditions. Nonetheless, further studies are required to investigate the efficiency of the strain BMNF7 for biodegradation of different organic pollutants and enzymes involved in this process. Bearing in mind the efficiency of local bacterial strains in pesticide degradation was found to be substantially higher than that of the introduced strains which may be attributed to outcompeting, biotic and/or abiotic interacting factors.

\section{References}

[1]. Abouseada, N., Moheb, M. and Moez, P. (2016). Impact of MALDI-TOF in the Routine Diagnostic Microbiology Laboratory in Alexandria University, Egypt. Egypt. J. Med. Microbiol., 3:616-620.

[2]. Adawiyah, I. (2008). Isolation, characterization and identification of microorganism from soil contaminated with pesticide (Doctoral dissertation, Universiti Malaysia Pahang).

[3]. Agarry, S.E., Olu-Arotiowa, O.A., Aremu, M.O., and Jimoda, L.A. (2013). Biodegradation of Dichlorovos (Organophosphate Pesticide) in soil by bacterial isolates. Journal of Natural Sciences Research, 3(8):12-16.

[4]. Agwa H, Aly MM, Bonaly R (2000). Isolation and characterization of two Streptomyces species produced non polyenic antifungal agents. J. Union Arab Biol. 7:62-82.

[5]. Anderson, M.J., Gorley, R.N. and Clarke, K.R. (2008). PERMANOVA for PRIMER: Guide to Software and Statistical Methods. PRIMER-E: Plymouth, UK. 214 pp.

[6]. Bala, M., Kaur,C., Kaur, I., Khan, F., and Mayilraj, S. (2012). Kocuriasediminis sp. nov, isolated from a marine sediment sample. Antonie Van Leeuwenhoek. 3:469-478.

[7]. Barragan-Huerta, B.E., Costa-Perez, C., Peralta-Cruz, J., Barrera-Cortes J., Esparza-Garcia, F. and Rodriguez-Vazquez, R. (2007). Biodegradation of organochlorine pesticides by bacteria grown in microniches of the porous structure of green bean coffee. Int. Biodet. Biodeg., 59: 239-244.

[8]. Chapalamadugu, S., Chaudhry, G.R. (1992). Microbiological and biotechnological aspects of metabolism of carbamates and organophosphates. Critical reviews in biotechnology, 12(5-6):357-89.

[9]. Chatzigeorgiou, K.S., Sergentanis, T.N., Tsiodras, S., Hamodrakas, S.J., Bagos, P.G. (2011). Phoenix 100 versus Vitek 2 in the identification of gram-positive and gram-negative bacteria: A comprehensive meta-analysis. J. Clin. Microbiol., 49:3284-3291.

[10]. Chun, J., Lee, J.H., Jung, Y., Kim, M., Kim, S., Kim, B.K.and Lim, Y.W. (2007). Extaxon: a web-based tool for the identification of prokaryotes based on 16S ribosomal RNA gene sequences. Int. J. Syst. Evol. Microbiol., 57(10):2259-2261.

[11]. Das, N. and Chandran, P. (2011). Microbial Degradation of petroleum hydrocarbon contaminants. An Overview Biotechnology Research Vol. 2011, Article ID 941810, 13 pages.

[12]. Ferjani, R., Marasco, R., Rolli, E. (2015). "The date palm tree rhizosphere is a niche for plant growth promoting bacteria in the oasis ecosystem". BioMed Research International, Vol. 2015, Article ID 153851, 10 pages.

[13]. George, A.O. A. (1990). Simple and readily available method for packed cell volume determination. Trop. Doct., 20(2):76-77.

[14]. Ghosh, P.G., Sawant, N.A, PatilS.N and Aglave, B.A. (2010). Microbial Biodegradation of Organophosphate Pesticides. International Journal of Biotechnology and Biochemistry, 6(6): 871-876.

[15]. Hassan, R.M., Bassiouny, D.M. and Matar, Y. (2016). Bacteremia caused by Kocuria kristinae from Egypt: Are there more?. A Case Report and Review of the Literature. Case Reports in Infectious Diseases, 31:1-4.

[16]. Jarallah, E. M., Mizher, A., and Abbas, A. (2016). Isolation and identification of degrading bacteria from agricultural soils and evaluation of their activity. Pure and Applied Sciences, 24(2) 112-128.

[17]. Kamil, M. and Naji M.A. (2012). New dimension and challenges for sustainable date palm production. Khalifa International Date Palm Award. 7 April at Emirates Palace Hotel in Abu Dhabi.

[18]. Kenneth, D.R., Dennis, A.L., Mark, R.S. (1990). Resistance of chlorpyrifos to enhanced biodegradation in soil. J. Agric. Food Chem., 38 (6): 1430-1436.

[19]. Khalifa, A.Y. and Almalki, M.A. (2015). Isolation and characterization of an endophytic bacterium, Bacillus megaterium BMN1, associated with root-nodules of Medicago sativa L. growing in Al-Ahsaa region, Saudi Arabia. Ann. Microbiol., 2:1017-1026.

[20]. Khani, M. and Kafilzadeh, F. (2014). Diazinon degradation by Pseudomonas earuginosa and Flavobacterium bacteria and assessing the growth Kinetics. Journal of Biology and Today's World, 4 (2): 44-48.

[21]. Kumar, S. (2011) Bioremediation of chlorpyrifos by bacteria isolated from the cultivated soils. Biotechnology, 3( 3) : 359-366. 
[22]. Mahiudddin, M., Fakhruddin, A.N.M., Abdullah-Al-M, Chowdhury, M.A.Z., Rahman, M.A., and Alam, M. K. ( 2014). Degradation of the organophosphorus insecticide Diazinon by soil bacterial isolate. J. Biotechnology, 3(1): 12-23.

[23]. Mallick, K., Bharati, K., Banerji, A., Shakil, N.A., Sethunathan, N. (1999). Bacterial degradation of chlorpyrifos in pure cultures and in soil. Bulletin of Environmental Contamination and Toxicology, 62(1):48-54.

[24]. Naphade, S.R., Durve, A. A., Bhot , M., Varghese J., and Chandra N. (2012). Isolation, characterization and identification of pesticide tolerating bacteria from garden soil. European Journal of Experimental Biology, 2 (5):1943-1951.

[25]. Paim, T.G.D.S, Cantarelli ,V.V. and d'Azevedo, P.A. (2014). Performance of the Vitek 2 system software version 5.03 in the bacterial identification and antimicrobial susceptibility test: evaluation study of clinical and reference strains of Gram-positive cocci. Rev. Soc. Bras. Med. Trop., 3:377-381.

[26]. Phugare, S. and Suresh, S. (2011), Microbial systems for bioremediation of toxicants doctor of philosophy in biochemistry, Shivaji University, Kolhapur.

[27]. Reddy, G. V. P. and Bautista, J. R. (2012). Integration of the predatory mite Neoseiulus californicus and petroleum spray oil for control of Tetranychus marianae on eggplant. Biocontrol Science and Technology, 22: 1211-1220.

[28]. Sharif, D. I., and Mollick, M. (2013). Selective isolation of a gram negative carbamate pesticide degrading bacterium from brinjal cultivated soil. American Journal of Agricultural and Biological Sciences, 8 (4): 249-256.

[29]. Siddavattam, D., Khajamohiddin, S., Manavathi, B., Pakala, S.B., and Merrick, M. (2003). Transposon-like organization of the plasmid-borne organophosphate degradation (opd) gene cluster found in Flavobacterium sp. Applied and environmental microbiology, 69(5):2533-2539.

[30]. Singh, B.K. and Walker, A. (2006). Microbial degradation of organophosphorus compounds. FEMS Microbiol. Rev., 30: $428-471$.

[31]. Singh, B. K., Walker, A., Morgan, J. A. W., and Wright, D. J. (2003). Effects of soil pH on the biodegradation of chlorpyrifos and isolation of a chlorpyrifos-degrading bacterium. Appl. Environ. Microbiol., 69: 5198-5206.

[32]. Singh, D.K. (2008). Biodegradation and bioremediation of pesticide in soil: concept, method and recent developments. Indian J. Microbiol., 48: 35-40.

[33]. Tamura, K. and Nei, M. (1993) .Estimation of the number of nucleotide substitutions in the control region of mitochondrial DNA in humans and chimpanzees, Mol. Biol. Evol., 10(3):512-26.

[34]. Tamura, K., Peterson, D., Peterson, N., Stecher, G., Nei, M., Kumar, S. (2011). MEGA: Molecular evolutionary genetics analysis using maximum likelihood, evolutionary distance, and maximum parsimony methods. Mol. Biol. Evol., 28:2731-2739.

[35]. Theriot, C.M. and Grunden, A.M. (2011). Hydrolysis of organophosphorus compounds by microbial enzymes. Appl. Microbiol. Biotechnol., 89: 35-43.

[36]. Van Beilen, J.B. and Funhoff, E.G. (2007). Alkane hydroxylases involved in microbial alkane degradation. Appl. Microbiol. Biotechnol., 1:13-21.

[37]. Weisburg, W.G., Barns, S.M., Pelletier, D.A., Lane, D.J. (1991). 16S ribosomal DNA amplification for phylogenetic study. J. Bacteriol., 173(2):697-703.

[38]. Wu, M., Chen, L., Tian, Y., Ding, Y. and Dick, W.A. (2013). Degradation of olycyclic aromatic hydrocarbons by microbial consortia enriched from three soils using two different culture media. Environ. Pollut., 178:152-158.

Table 1. Growth and degradation of Diazinon in solid (diameter of clear zone $\mathrm{cm}$ ) and liquid minimal salt medium and the three selected bacterial isolates

\begin{tabular}{|c|c|c|c|c|}
\hline \multirow{3}{*}{ Tested isolate } & \multicolumn{2}{|c|}{ Growth in broth medium } & \multicolumn{2}{|c|}{ Degradation } \\
\hline & \multirow{2}{*}{$\mathbf{A}_{440 \mathrm{~nm}}$} & \multirow{2}{*}{$\begin{array}{c}\text { Cell Packed } \\
\text { Volume (CPV) }\end{array}$} & \begin{tabular}{|l|} 
In solid medium \\
\end{tabular} & In liquid medium \\
\hline & & & $\begin{array}{l}\text { Diameter of the clear zone } \\
(\mathrm{cm})\end{array}$ & $\%$ degradation \\
\hline BMR F3 & $0.68 \pm 0.2$ & 22 & $5.1 \pm 2.1$ & 30 \\
\hline BMN F7 & $0.54 \pm 0.10$ & 25 & $7.0 \pm 1.1$ & 33 \\
\hline BMT F 8 & $0.49 \pm 0.19$ & 24 & $4.1 \pm 1.5$ & 21 \\
\hline
\end{tabular}
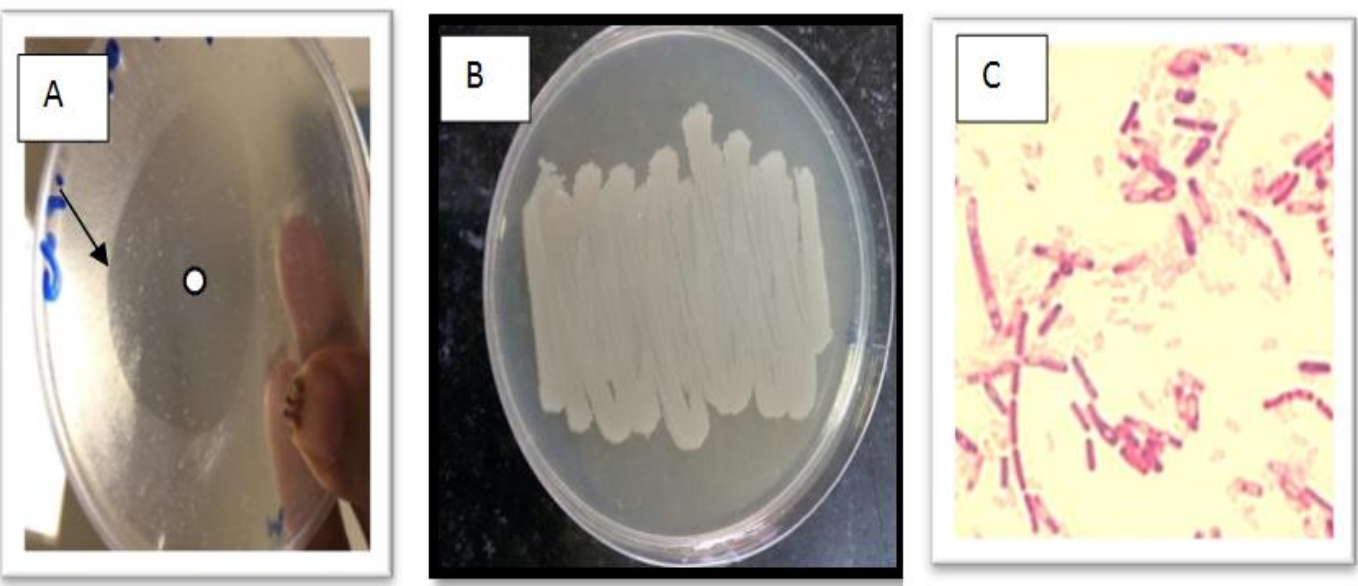

Fig. 1. The selected isolate on minimal agar medium containing Diazinon as carbon source (A), on Nutrient agar (B), and under light microscope after Gram staining (C) 


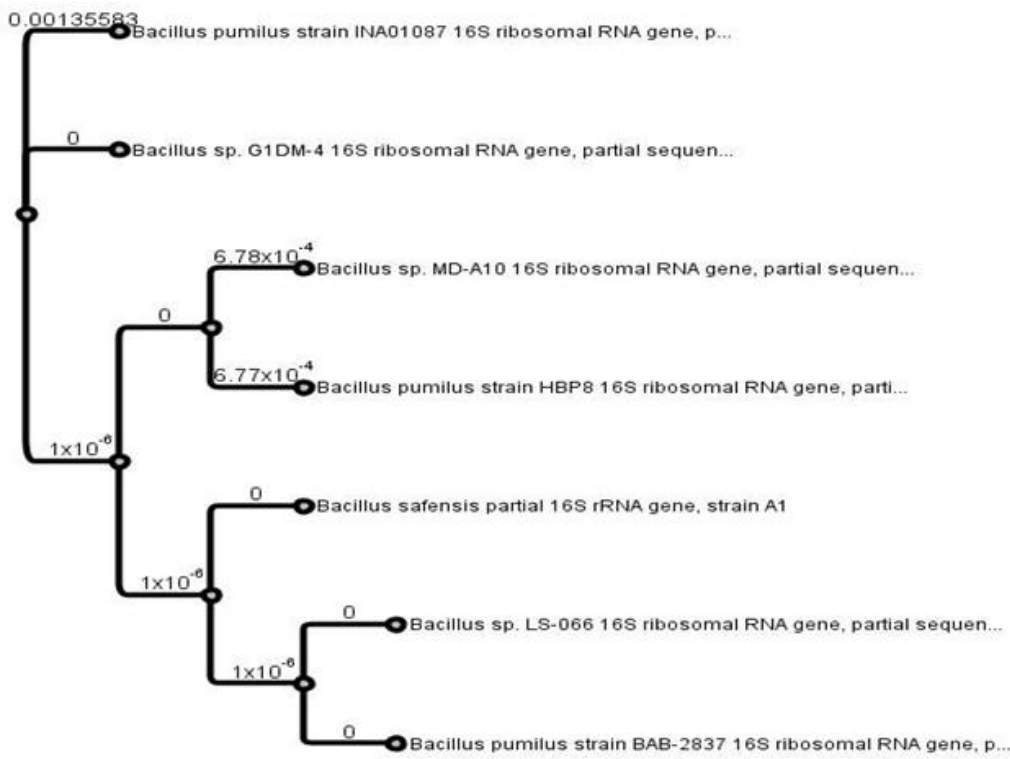

Fig. 2. Phylogenetic tree based on $16 \mathrm{~S}$ rRNA gene comparison of the bacterial strain and other bacteria

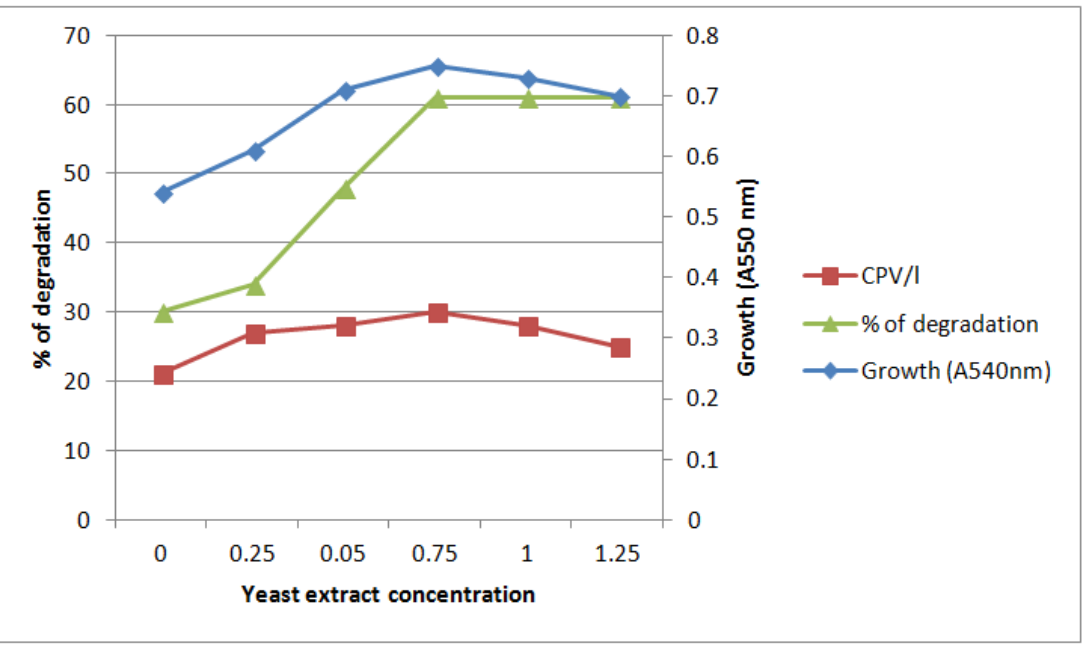

Fig.3. Effect of different concentrations of yeast extracts on growth and \% of Diazinon degradation by the isolate BMNF7

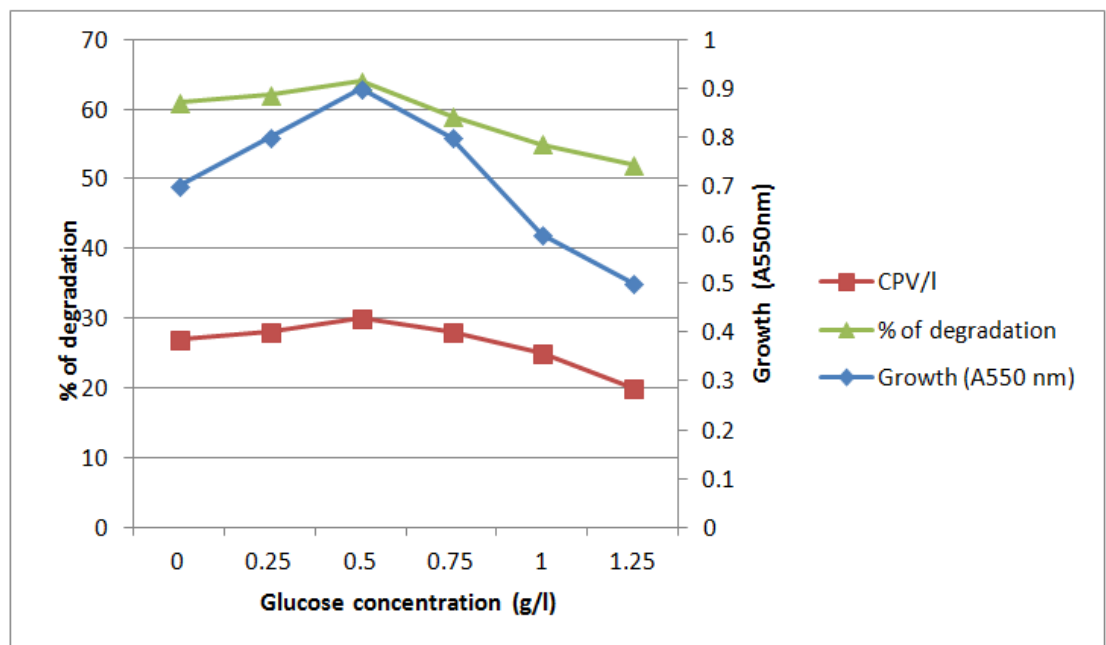

Fig.4. Effect of different glucose concentrations on growth and \% of Diazinon degradation by the isolate BMNF7 


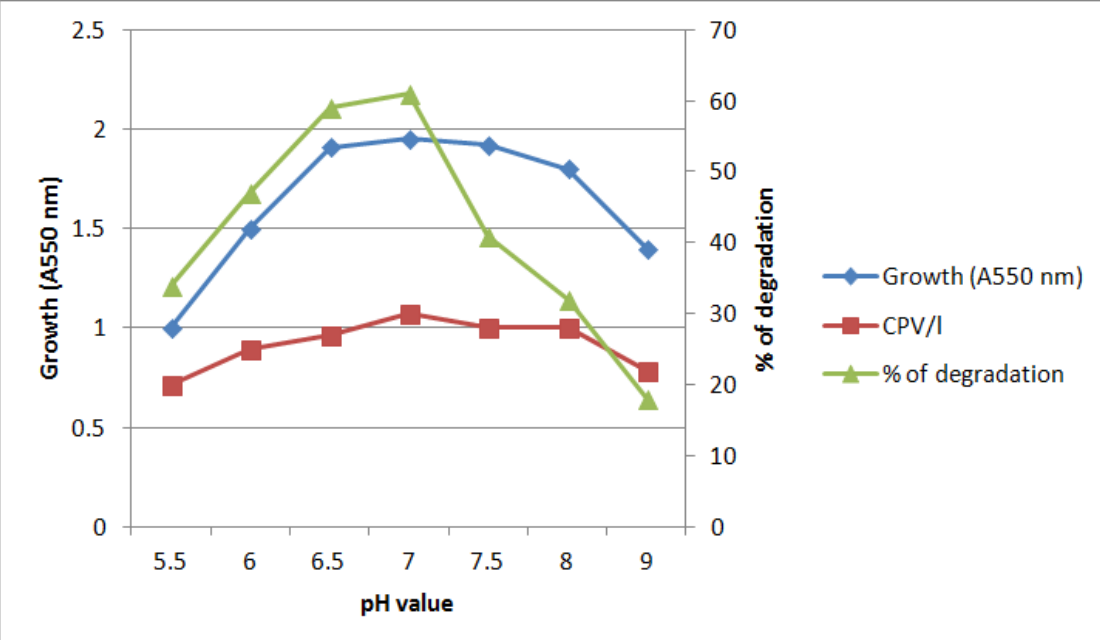

Fig.5. Effect of different $\mathrm{pH}$ values on growth and \% of Diazinon degradation by the isolate BMNF7

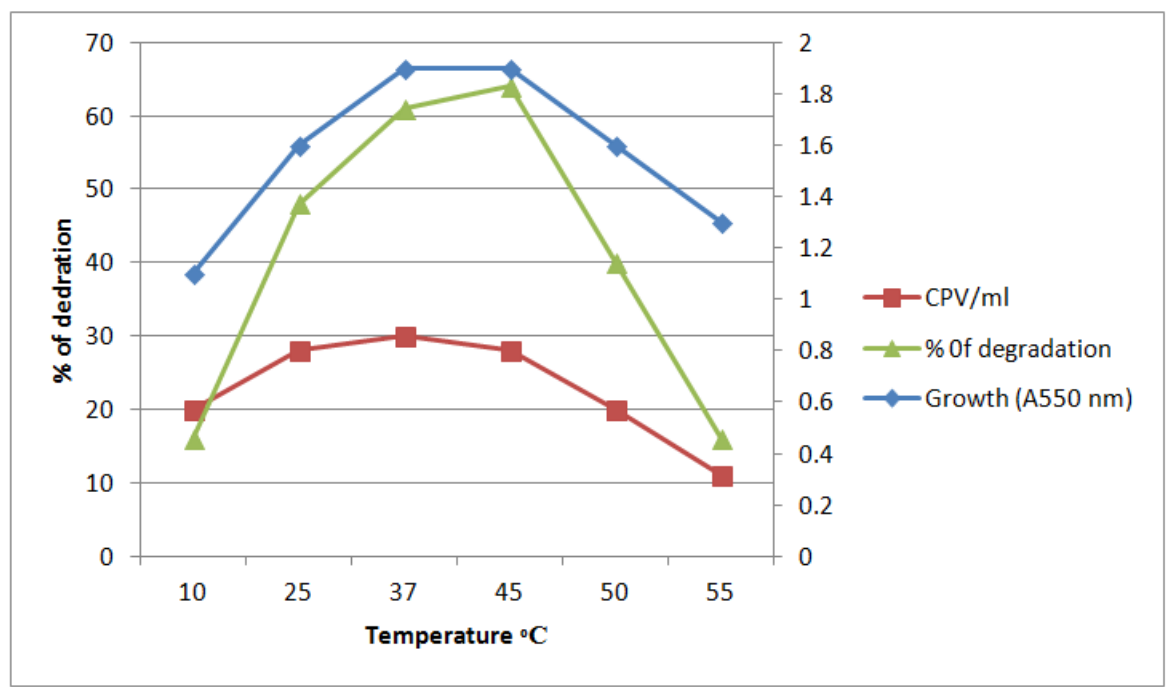

Fig.6. Effect of different incubation temperature on growth and \% of Diazinon degradation by the isolate BMNF7

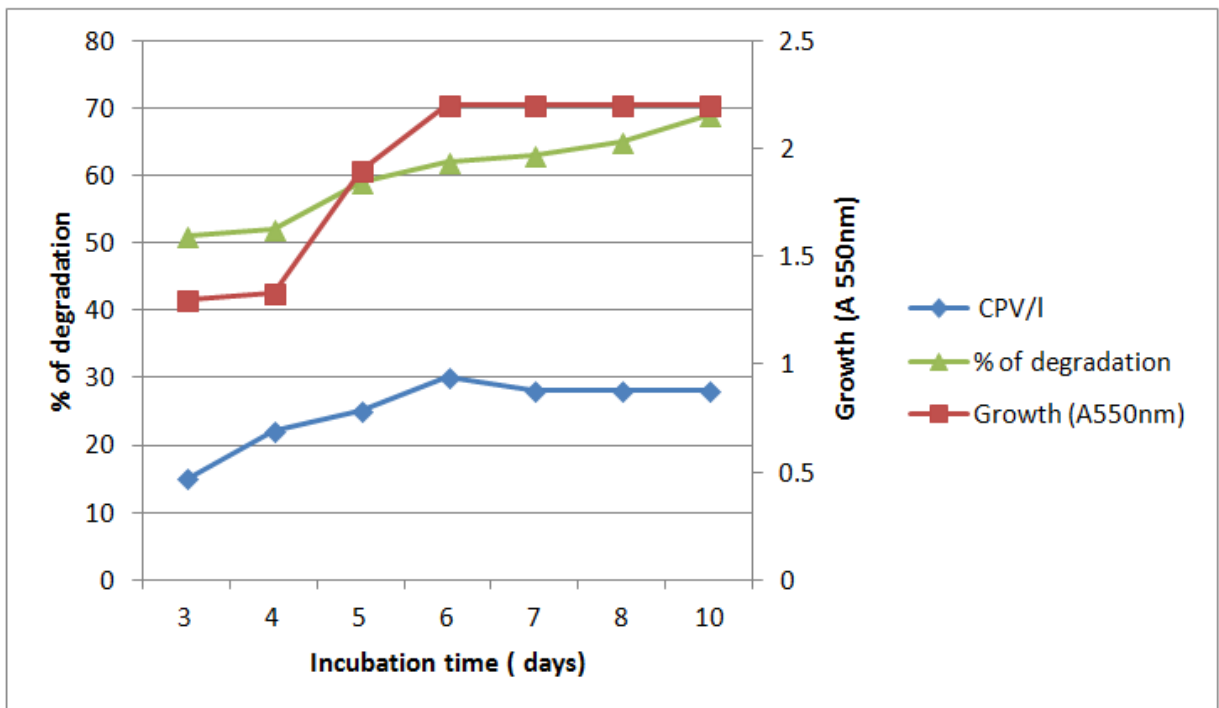

Fig.7. Effect of different incubation time on growth and \% of Diazinon degradation by the isolate BMNF7 


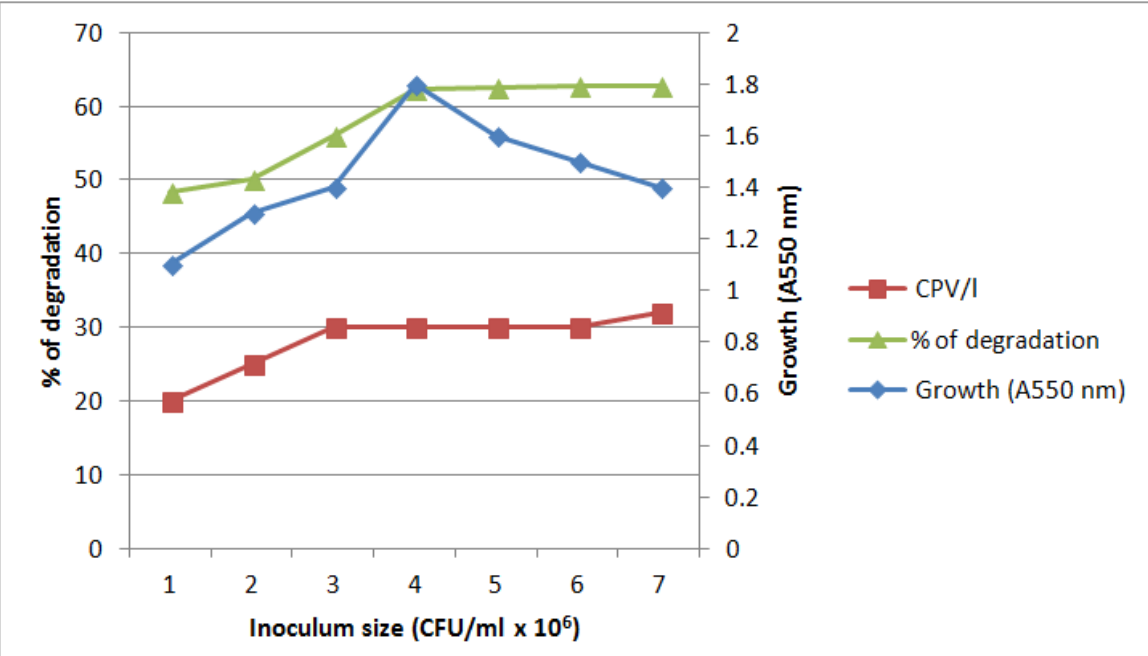

Fig.8. Effect of different inoculum size on growth and \% of Diazinon degradation by the isolate BMNF7 